\title{
Correction to: ASO Author Reflections: Cumulative GRAS Score Predicts Outcomes After Resection for Adrenal Cortical Carcinoma
}

\author{
Jordan J. Baechle, BS ${ }^{1}$, Paula Marincola Smith, $\mathrm{MD}^{2}$, and Colleen M. Kiernan, $\mathrm{MD}^{2}$ \\ ${ }^{1}$ School of Medicine, Meharry Medical College, Nashville, TN; ${ }^{2}$ Division of Surgical Oncology and Endocrine Surgery, \\ Department of Surgery, Vanderbilt University Medical Center, Nashville, TN
}

\section{CORRECTION TO:}

ANN SURG ONCOL

HTTPS://DOI.ORG/10.1245/S10434-021-09616-5

Jordan J. Baechle and Paula Marincola Smith contributed equally to this paper. The original article has been updated.
Publisher's Note Springer Nature remains neutral with regard to jurisdictional claims in published maps and institutional affiliations.

The original article can be found online at https://doi.org/10.1245/ s10434-021-09616-5.

(C) Society of Surgical Oncology 2021

Published Online: 17 February 2021

C. M. Kiernan, MD

e-mail: colleen.m.kiernan@vumc.org 